\title{
Recent Trend for Endovascular Treatment in Patients with Acute Ischemic Stroke: Balloon Guide Catheter
}

\author{
Chong Hyun Suh, $\mathrm{MD}^{1}$, Young-Jun Lee, $\mathrm{MD}, \mathrm{PhD}^{2}$
}

${ }^{1}$ Department of Radiology and Research Institute of Radiology, Asan Medical Center, University of Ulsan College of Medicine, Seoul, Korea

${ }^{2}$ Department of Radiology, Hanyang University Hospital, Hanyang University College of Medicine, Seoul, Korea
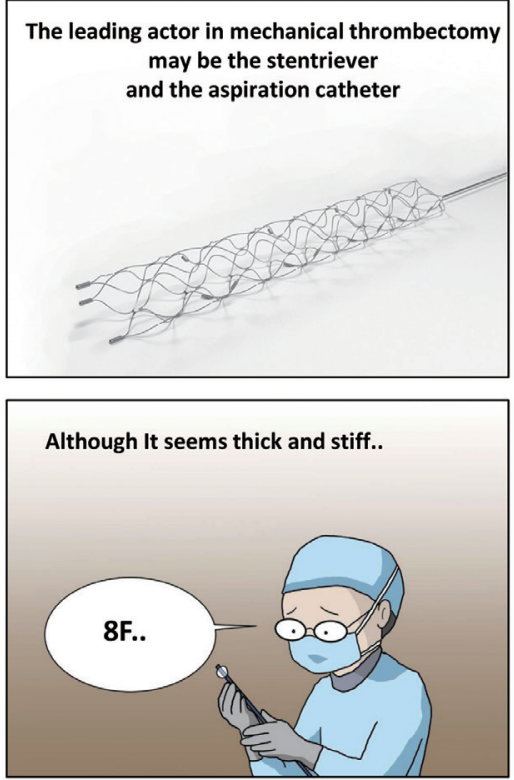

According to the recent publication in Stroke, successful recanalization rate and first pass recanalization rate were significantly higher in the BGC group compared to non-BGC group.

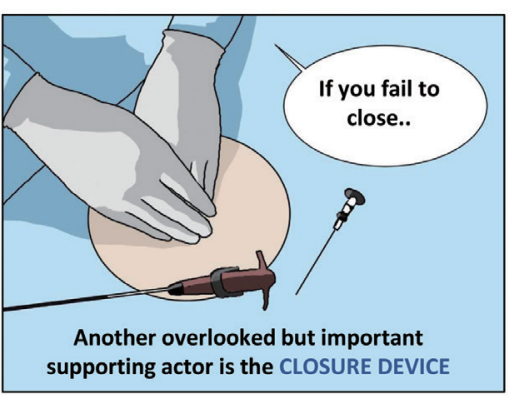

You will sit up all night compressing the puncture site ) instead of enjoying the joy of successful recanalization

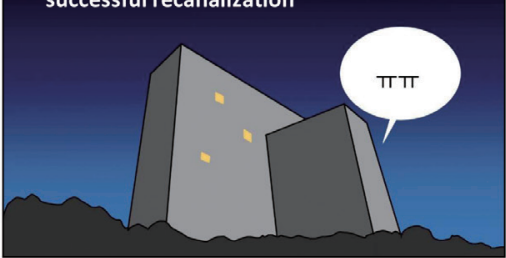

\section{Correspondence to:}

Young-Jun Lee, MD, PhD

Department of Radiology, Hanyang

University Hospital, Hanyang Uni-

versity College of Medicine, 222-1

Wangsimni-ro, Seongdong-gu, Seoul

04763, Korea

Tel: +82-2-2290-9153

Fax: +82-2-2293-2111

E-mail: yjleeee@hanyang.ac.kr

Received: June 20, 2019

Revised: August 8, 2019

Accepted: August 12, 2019
Copyright $\odot 2019$ Korean Society of Interventional Neuroradiology

This is an Open Access article distributed under the terms of the Creative Commons Attribution Non-Commercial License (http://creativecommons.org/licenses/by-nc/3.0) which permits unrestricted non-commercial use, distribution, and reproduction in any medium, provided the original work is properly cited. 
In the era of endovascular treatment for patients with acute ischemic stroke, fast and complete recanalization of the occluded vessel are associated with improved outcomes. To achieve this goal, the balloon guide catheter as well as stentriever or distal access catheter plays an important role. By infilating the balloon, the balloon guide catheter can arrests antegrade flow, which prevents distal migration of clots and enhances aspiration force.

In a recent meta-analysis, patients treated with a balloon guide catheter for mechanical thrombectomy showed higher odds of first-pass recanalization (odds ratio [OR], 2.1; 95\% confidence interval $[\mathrm{Cl}], 1.7-2.6)$ and modified Rankin Scale 0-2 (OR, 1.84; 95\% Cl, 1.5-2.2) compared to non-balloon guide catheter group. ${ }^{1}$ Baek et al. ${ }^{2}$ investigated the effect of the balloon guide catheter not only in mechanical thrombectomy but also in aspiration thrombectomy. The balloon guide catheter group demonstrated significantly higher successful recanalization rate (87\%) and higher first-pass recanalization rate (37\%) compared to those of non-balloon guide catheter group (75\% and 14\%, respectively; $\mathrm{P}<0.001$ each). In addition, the balloon guide catheter group revealed a significantly fewer number of device passes (2.5) and shorter procedural time (54 minutes) compared to those of non-balloon guide catheter group (3.3 and 68 minutes, respectively; $\mathrm{P}<0.001$ each). Moreover, the use of a balloon guide catheter was an independent factor for successful recanalization (OR, $2.2 ; 95 \% \mathrm{Cl}, 1.5-3.1)$ and a favorable outcome (OR, 1.4; 95\% $\mathrm{Cl}, 1.0-1.9)$ regardless of the type of first-line endovascular modality used. The European Stroke Organisation (ESO) European Society for Minimally Invasive Neurological Therapy (ESMINT) guideline recommends that any mechanical thrombectomy procedure should be preferably conducted together with a proximal balloon guide catheter. ${ }^{3}$

In summary, the balloon guide catheter by using mechanical thrombectomy as well as aspiration thrombectomy in endovascular treatment for acute ischemic stroke may be beneficial in terms of recanalization success and functional outcome.

\section{REFERENCES}

1. Brinjikji W, Starke RM, Murad MH, Fiorella D, Pereira VM, Goyal M, et al. Impact of balloon guide catheter on technical and clinical outcomes: a systematic review and meta-analysis. J Neurointerv Surg 2018;10:335-339

2. Baek JH, Kim BM, Kang DH, Heo JH, Nam HS, Kim YD, et al. Balloon guide catheter is beneficial in endovascular treatment regardless of mechanical recanalization modality. Stroke 2019;50:1490-1496

3. Turc G, Bhogal P, Fischer U, Khatri P, Lobotesis K, Mazighi M, et al. European Stroke Organisation (ESO)- European Society for Minimally Invasive Neurological Therapy (ESMINT) guidelines on mechanical thrombectomy in acute ischemic stroke. J Neurointerv Surg 2019;11:535-538 